Article

\title{
Mechanical Properties and Characteristics of the Anterolateral and Collateral Ligaments of the Knee
}

\author{
Ho-Jung Cho and Dai-Soon Kwak * (D) \\ Catholic Institute for Applied Anatomy/Department of Anatomy, College of Medicine, the Catholic University of \\ Korea, 222, Banpo-daero, Seocho-gu, Seoul 06591, Korea; modern0901@gmail.com \\ * Correspondence: daisoon@catholic.ac.kr; Tel.: +82-2-2258-7434; Fax: +82-303-3448-7878
}

Received: 5 August 2020; Accepted: 7 September 2020; Published: 9 September 2020

\begin{abstract}
Biomechanical studies assessing the major knee ligaments, such as the anterior cruciate ligament, posterior cruciate ligament, medial collateral ligament (MCL), and lateral collateral ligament (LCL), have been conducted using various methodologies. However, despite the anterolateral ligament (ALL) being regarded as the important ligament for the stability of the knee, a lack of biomechanical research focusing on the ALL exists to date. Moreover, studies assessing the relative mechanical properties of each ligament of the knee are insufficient. Therefore, this study examined the mechanical properties of the ALL, MCL, and LCL and considered the relative differences between these ligaments. Twenty-one fresh cadaver knees were chosen to investigate the mechanical properties. The width, thickness, and length were measured. The stiffness, ultimate load, and elastic modulus were also tested. The MCL showed the greatest ultimate load $(498.5 \mathrm{~N})$ and the highest stiffness $(71.97 \mathrm{~N} / \mathrm{mm})$, and the ALL presented the smallest ultimate load $(146.64 \mathrm{~N})$ and lowest stiffness $(42.62 \mathrm{~N} / \mathrm{mm})$. Meanwhile, the LCL was second concerning the ultimate load $(263.22 \mathrm{~N})$ and stiffness $(69.70 \mathrm{~N} / \mathrm{mm})$. The elastic modulus of the LCL (493.86 MPa) was greater than those of both the MCL and ALL (326.75 MPa and $345.27 \mathrm{MPa}$, respectively). There was no difference between the sides according to the different properties of all the ligaments. A sex difference was apparent only concerning the ultimate load for all the ligaments. Each ligament showed similar stiffness irrespective of its size; for this reason, stiffness should be considered initially and while conducting biomechanical simulations of these ligaments.
\end{abstract}

Keywords: mechanical property; knee ligament; medial collateral ligament; lateral collateral ligament; anterolateral ligament

\section{Introduction}

Anatomically, several ligaments are located around the knee joint. Among these, the major ligaments of the knee joint that contribute to stability include the anterior cruciate ligament (ACL), posterior cruciate ligament (PCL), medial collateral ligament (MCL), and lateral collateral ligament (LCL) [1,2]. In addition, the anterolateral ligament (ALL) has recently come to be considered a key ligament that ensures the stability of the knee joint $[3,4]$. These are considered as important structures in the field of biomechanical studies, ligament reconstruction for knee replacement, or sports injuries [5-7]. Biomechanical studies for most of the major knee ligaments have already been performed to assess their mechanical properties, commonly including the ACL and PCL, which are considered the main knee ligaments. Kennedy et al. studied the mechanical properties and strain rate of the ACL and LCL [8], while Woo et al. investigated the properties of the ACL according to age and load direction [9]. Meanwhile, Chandrashekar et al. researched the ACL's tensile properties according to sex [10] and Haner et al. and Race and Amis each reported on the mechanical properties of the PCL [11,12]. Existing biomechanical studies have also focused on collateral ligaments. 
In 1976, Terry et al. reported the strength and yield load of the MCL and LCL using cadavers [13], while, elsewhere, Butler et al. studied the elastic modulus and yield stress of the LCL using young cadavers [14]. Separately, Robinson et al. researched yield load using the superficial and deep layers of the medial collateral ligament [15] and Wilson et al. suggested mechanical properties of the medial and lateral collateral ligaments [16]. Several other researchers have also focused on understanding the existence, morphological features, and role of the ALL [17-19]. Conversely, the mechanical properties of the ALL have been researched but only to a basic level as few studies to date have been published [20-23]. Moreover, although the various mechanical properties of the major knee ligaments have been studied, these studies only focus on individual target ligaments. Thus, there remains a lack of research assessing the relative mechanical properties of each ligament. This study therefore seeks to investigate the mechanical properties of the MCL, LCL, and ALL using the same knee and to analyze the relative variation between these ligaments.

\section{Materials and Methods}

\subsection{Specimen Preparation}

Twenty-one knees from fresh-frozen Korean cadavers donated to the Catholic University of Korea ( $\mathrm{n}=12$ female and $\mathrm{n}=9$ male) were used to evaluate the mechanical properties of the major ligaments of the knee (Table 1). The side configuration was 14 bilateral and seven unilateral knees. The mean age of the samples was 79.1 years old (range: 62-93 years).

Table 1. Specimen information.

\begin{tabular}{cccccc}
\hline ID & Sex & Age & Height (cm) & Weight (kg) & Side (21 Sides) \\
\hline S01 & M & 68 & 130 & 44 & Left \\
\hline S02 & M & 73 & 160 & 70 & Right \\
\hline S03 & F & 76 & 156 & 48 & Both \\
\hline S04 & F & 85 & 137 & 38 & Right \\
\hline S05 & M & 71 & 157 & 46 & Right \\
\hline S06 & M & 77 & 163 & 78 & Both \\
\hline S07 & M & 68 & 162 & 42 & Left \\
\hline S08 & M & 62 & 166 & 28 & Right \\
\hline S09 & F & 77 & 147 & 40 & Both \\
\hline S10 & M & 78 & 172 & 50 & Both \\
\hline S11 & F & 86 & 150 & 26 & Both \\
\hline S12 & F & 93 & 152 & 44 & Both \\
\hline S13 & F & 95 & 162 & 36 & Both \\
\hline S14 & F & 71 & 155 & 52 & Right \\
\hline & F: 7 & 77.1 & 154.9 & 45.9 & Rt: 5 \\
& M: 7 & & & Lt: 2 \\
\hline
\end{tabular}

\subsection{Dissection and Specimen Preparation}

Skin and subcutaneous tissues were removed from the mid-shaft of the femur to the mid-shaft of the tibia. On the lateral part of the knee, the iliotibial tract was carefully detached from the proximal thigh to its insertion, including the deepest layer of the iliotibial tract. When the ALL was found to be existing on the LCL superficially, the borders of the ALL and LCL were carefully dissected. On the 
medial part of the knee, the MCL was also found after removing the muscles of the medial part of the knee.

Following dissection, the anthropometric measurement procedure was performed. The thickness and width of the ligaments at the joint line were measured and the length of the ligaments at the knee extension was defined as the linear distance from the femoral attachment to the tibial or fibular attachment. Digital calipers (CP150; Mitutoyo, Kawasaki, Japan) was used during the anthropometric measurement procedure.

\subsection{Material Testing}

After the measurement procedure, fixation procedures were performed to facilitate the material testing. The distal femur was cut at a 50-mm distance from the proximal attachment of the MCL and the LCL. The tibia was also cut at a 50-mm distance from the distal attachment of the MCL and the tibia part was sectioned at the mid-sagittal plane for individual testing of the MCL and ALL, respectively. This mid-sagittal section of the tibia was capable of supporting independent material testing of the MCL and LCL from the same knee. After the cutting procedures were completed, one femoral fixture part and two tibial parts (MCL/LCL) and one fibular part (ALL) were fixed with polymethyl methacrylate (PMMA, Fricke Dental International Inc, Streamwood, IL, USA) for material testing (Figure 1).
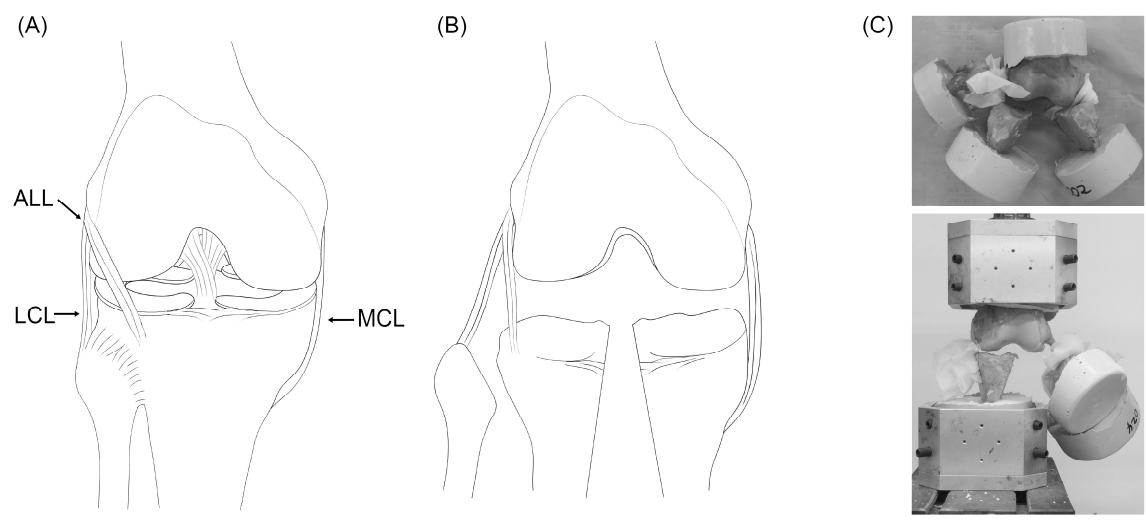

Figure 1. Specimen preparation procedures for material testing. (A) Dissections for exposing the lateral collateral ligament (LCL), anterolateral ligament (ALL), and medial collateral ligament (MCL). (B) Mid-sagittal cutting for testing. (C) Specimen fixation: femur pair with fibular for the LCL test; femur pair with the lateral part of the tibia for the ALL test; and femur pair with the medial part of the tibia for the MCL test.

A universal test machine (5567; Instron, Norwood, MA, USA) with a custom-made jig was used to perform the mechanical testing with a position accuracy of $0.02 \mathrm{~mm}$ and a load accuracy of $0.1 \mathrm{~N}$ (Load cell 2525-805, 5kN, Instron, Norwood, MA, USA). The femoral part was fixed to the upper jig and the medial section of the tibia part was fixed to the lower jig for the MCL test. After the MCL test, the fibular part was fixed to the lower jig for the ALL test and the lateral part of the tibia was fixed to the lower jig for the LCL test, respectively, with the femoral part remaining fixed to the upper jig in both cases. The lower jig had an $\mathrm{X}-\mathrm{Y}$ moving table for knee alignment. The initial tension of $10 \mathrm{~N}$ was applied for straightening the ligaments, and then the displacement was applied at a rate of $10 \mathrm{~mm} / \mathrm{min}$ to measure the tensile force until failure of the ligament occurred [23,24]. During mechanical testing, normal saline was sprayed onto the specimen to prevent dehydration of the ligaments. After detachment from the test frame, the specimens were visually inspected for the mode of failure.

\subsection{Data Acquisition and Analysis}

The load and displacement channel data from the universal test machine were saved. The stiffness was calculated from the initial linear region of the load and displacement curve and the ultimate 
load was thereafter detected from the load and displacement curve (Figure 2). By applying the width, thickness, and length data measured before the test, the stiffness, ultimate load, and elastic modulus were calculated. The cross-sectional area of the ALL and MCL were calculated by considering it as a rectangular shape and that of the LCL was calculated as an oval shape. Data analysis was performed using Bluehill software (Instron, Norwood, MA, USA) and its "Automatic modulus" analysis library for stiffness and the "E-Modulus" analysis library for the elastic modulus. Using these analysis procedures, we first revealed the mechanical properties of the MCL, LCL, and ALL and then clarified the side (left vs. right knee) and sex differences. The data are presented as the mean \pm standard deviation unless otherwise specified. The paired $t$-test was used to compare the stiffness, ultimate load, and elastic modulus between the ligaments. Any test was considered to be statistically significant if the associated $p$-value was 0.05 or less.

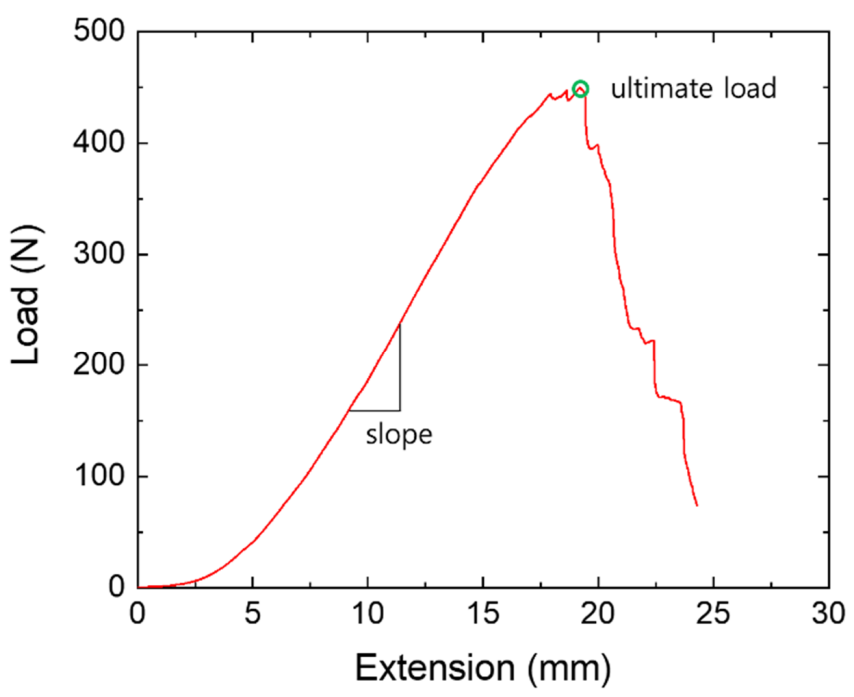

Figure 2. An MCL test curve and ultimate load, stiffness, and elastic modulus calculation. The slope represents stiffness in the load-extension curve and represents the elastic modulus in the stress-strain curve.

\section{Results}

The results of the morphological measurements of the MCL, ALL, and LCL are shown in Table 2. The width and thickness were measured at the joint line and the length was measured as the distance from the proximal to the distal attachments of each ligament. When reviewing the results of the width of the ligaments, the widest ligament was the MCL and the narrowest one the LCL; also, the mean widths of the MCL, ALL, and LCL were $11.19 \mathrm{~mm}, 5.49 \mathrm{~mm}$, and $3.96 \mathrm{~mm}$, respectively $(p<0.01)$. The mean thickness values of the LCL and MCL were $2.58 \mathrm{~mm}$ and $2.14 \mathrm{~mm}$, respectively, and there was no statistical difference between the LCL and MCL ( $p=0.09)$; meanwhile, that of the ALL was $1.52 \mathrm{~mm}$, indicating it was the thinnest ligament relative to the other two $(p<0.01)$.

Table 2. Size measurement results of the ligaments.

\begin{tabular}{cccc}
\hline & MCL & ALL & LCL \\
\hline Width $(\mathrm{mm})$ & $11.19 \pm 2.78$ & $5.49 \pm 1.90$ & $3.96 \pm 0.98$ \\
Thickness $(\mathrm{mm})$ & $2.14 \pm 0.70$ & $1.52 \pm 0.64$ & $2.58 \pm 0.95$ \\
Length $(\mathrm{mm})$ & $68.99 \pm 19.01$ & $34.00 \pm 9.90$ & $48.15 \pm 5.79$ \\
Cross-sectional area $\left(\mathrm{mm}^{2}\right)$ & $24.54 \pm 11.94$ & $8.50 \pm 5.06$ & $8.76 \pm 3.77$ \\
\hline
\end{tabular}

Table 3 presents the results of the mechanical properties elucidated using the universal test machine. The ultimate loads, which initiate ligament damage, according to the individual ligaments were as follows: MCL, $498.57 \mathrm{~N}$; LCL, $263.22 \mathrm{~N}$; and ALL, $146.64 \mathrm{~N}(p<0.01)$. The stiffness of the 
$\operatorname{MCL}(71.97 \mathrm{~N} / \mathrm{mm})$ was greater than that of the LCL $(69.70 \mathrm{~N} / \mathrm{mm})$; however, there was no significant difference $(p=0.75)$. The stiffness of the ALL was smallest among the ligaments $(42.62 \mathrm{~N} / \mathrm{mm})(p<0.01)$. The elastic modulus of the MCL (326.75 MPa) was similar to that of the ALL (345.27 MPa). Although the elastic modulus of the LCL was the largest in terms of its numerical value (493.86 MPa), there was no statistically significant difference relative to the values of the other ligaments $(p=0.06)$.

Table 3. Test results of the mechanical properties of the ligaments.

\begin{tabular}{cccc}
\hline & MCL & ALL & LCL \\
\hline Ultimate load (N) & $498.57 \pm 119.56$ & $146.64 \pm 53.56$ & $263.22 \pm 93.09$ \\
Stiffness (N/mm) & $71.97 \pm 23.47$ & $42.62 \pm 21.26$ & $69.70 \pm 22.89$ \\
Elastic modulus (MPa) & $326.75 \pm 225.22$ & $345.27 \pm 293.03$ & $493.86 \pm 98.97$ \\
\hline
\end{tabular}

The damaged areas of the different ligaments that appeared during the failure test are described in Table 4. The damaged area in the MCL and ALL most prominently involved the mid-substance of the ligament at rates of $48 \%$ (10/21 cases) and 67\% (14/21 cases), respectively. However, $48 \%$ (10/21 cases) of the LCL was damaged at the proximal attachment of the ligament, which includes the femoral attachment part of the LCL. All ligaments had the least damage present at the distal attachment point (i.e., where the ligament attached to the tibia or fibula).

Table 4. Failure mode of the ligaments.

\begin{tabular}{cccc}
\hline Damaged Area & MCL & ALL & LCL \\
\hline Proximal attachment & 7 & - & 10 \\
Mid-substance & 10 & 14 & 4 \\
Distal attachment & 4 & 7 & 7 \\
\hline
\end{tabular}

There was a clear dominant side of the upper and lower extremities dependent on the individual under assessment. The right-left difference might be apparent because the dominant side more often handled major movements and power. Therefore, the MCL, ALL, and LCL properties of this study were compared between the left and right sides (Table 5). There was no difference between the sides among all properties of the ligaments assessed in this study. Concerning differences in the properties according to sex, the ultimate load of the male cadavers was greater than that of the female cadavers for all ligaments $(p<0.05)$. Moreover, the stiffness and elastic modulus of the male cadavers were greater than those of the female cadavers as numerical values but there was no significant difference in this regard between the sexes.

Table 5. Side and sex differences among the ligaments.

\begin{tabular}{|c|c|c|c|c|c|c|c|}
\hline & & \multicolumn{3}{|c|}{ Side } & \multicolumn{3}{|c|}{ Sex } \\
\hline & & $\begin{array}{c}\text { Left } \\
(n=9)\end{array}$ & $\begin{array}{c}\text { Right } \\
(n=12)\end{array}$ & $p$-Value & $\begin{array}{l}\text { Female } \\
(n=12)\end{array}$ & $\begin{array}{c}\text { Male } \\
(n=9)\end{array}$ & $p$-Value \\
\hline \multirow{3}{*}{ MCL } & $\begin{array}{l}\text { Failure load } \\
\text { (N) }\end{array}$ & $479.6 \pm 83.3$ & $512.8 \pm 142.9$ & 0.542 & $461.2 \pm 102.4$ & $568.5 \pm 108.2$ & 0.049 \\
\hline & $\begin{array}{l}\text { Stiffness } \\
(\mathrm{N} / \mathrm{mm})\end{array}$ & $68.5 \pm 24.8$ & $74.6 \pm 23.2$ & 0.569 & $67.6 \pm 25.5$ & $77.8 \pm 20.4$ & 0.338 \\
\hline & $\begin{array}{l}\text { Elastic modulus } \\
\qquad(\mathrm{MPa})\end{array}$ & $214.4 \pm 109.2$ & $382.9 \pm 205.0$ & 0.321 & $248.1 \pm 145.0$ & $425.1 \pm 289.9$ & 0.268 \\
\hline \multirow{3}{*}{ ALL } & $\begin{array}{l}\text { Failure load } \\
\qquad(\mathrm{N})\end{array}$ & $160.5 \pm 69.5$ & $136.3 \pm 37.7$ & 0.317 & $122.0 \pm 17.8$ & $179.5 \pm 67.9$ & 0.035 \\
\hline & $\begin{array}{l}\text { Stiffness } \\
(\mathrm{N} / \mathrm{mm})\end{array}$ & $42.5 \pm 17.3$ & $42.7 \pm 24.6$ & 0.985 & $37.8 \pm 18.1$ & $49.1 \pm 24.5$ & 0.236 \\
\hline & $\begin{array}{l}\text { Elastic modulus } \\
(\mathrm{MPa})\end{array}$ & $423.7 \pm 135.5$ & $306.0 \pm 152.8$ & 0.604 & $288.2 \pm 174.5$ & $416.6 \pm 319.7$ & 0.550 \\
\hline
\end{tabular}


Table 5. Cont.

\begin{tabular}{cccccccc}
\hline & \multicolumn{3}{c}{ Side } & \multicolumn{3}{c}{ Sex } \\
\cline { 2 - 7 } & & $\begin{array}{c}\text { Left } \\
(\mathbf{n}=\mathbf{9})\end{array}$ & $\begin{array}{c}\text { Right } \\
\mathbf{( n = 1 2 )}\end{array}$ & $p$-Value & $\begin{array}{c}\text { Female } \\
(\mathbf{n}=\mathbf{1 2})\end{array}$ & $\begin{array}{c}\text { Male } \\
(\mathbf{n}=\mathbf{9})\end{array}$ & $p$-Value \\
\hline \multirow{3}{*}{ LCL } & $\begin{array}{c}\text { Failure load } \\
(\mathrm{N})\end{array}$ & $275.8 \pm 127.6$ & $253.8 \pm 60.7$ & 0.642 & $214.1 \pm 27.3$ & $328.7 \pm 110.5$ & 0.014 \\
\cline { 2 - 7 } & $\begin{array}{c}\text { Stiffness } \\
(\mathrm{N} / \mathrm{mm})\end{array}$ & $61.3 \pm 17.3$ & $76.0 \pm 25.1$ & 0.149 & $63.2 \pm 24.3$ & $78.3 \pm 18.8$ & 0.139 \\
\cline { 2 - 7 } & $\begin{array}{c}\text { Elastic modulus } \\
(\mathrm{MPa})\end{array}$ & $438.7 \pm 74.3$ & $521.5 \pm 103.6$ & 0.263 & $476.0 \pm 119.8$ & $516.2 \pm 76.0$ & 0.579 \\
\hline
\end{tabular}

\section{Discussion}

The major ligaments of the knee joint include the ACL, PCL, LCL, and MCL; however, recently, many researchers have begun to focus on the ALL as a key ligament in orthopedic and anatomical studies of the knee. The ALL is located in the anterolateral region of the knee and assists the ACL. Therefore, it functionally resists the internal rotation and anterior translation of the tibia as a secondary stabilizer, thus reducing rotational laxity and the pivot shift [17,25-27].

Biomechanical assessments of the joint using computer simulation have been performed in various ways. The mechanical properties of major ligaments with roles in promoting stability of the knee and other joints should be researched to analyze the joint biomechanics [28]. The ACL, PCL, LCL, and MCL have been highlighted as the main ligaments to test the tensile properties of the knee joint. However, although the ALL was mentioned to have an important role in knee joint movement, a lack of research regarding ALL properties persists. Therefore, we researched the anatomical and mechanical parameters of the ALL, LCL, and MCL and compared them with one another.

In this study, the anatomical dimensions of the ALL, LCL, and MCL were measured in the same sample and the mechanical properties of these ligaments were tested using a universal test machine. According to the results of the anatomical dimensions and mechanical properties, the MCL, which showed the greatest values for the ultimate load and stiffness, was also the widest and thickest among the three ligaments. Meanwhile, the ALL, with the lowest ultimate load and least amount of stiffness, was thinner and shorter than the other two ligaments.

Previously, some researchers had mentioned that the ultimate load of the ALL might be different according to the anatomical description of the ALL $[3,29]$. The mean ultimate load reported by Rahnemai-Azar et al., who investigated the properties of the anterolateral knee capsule using nine samples, was $319.7 \mathrm{~N}$ and, among these nine samples, two knee capsules included the ALL [30]. In the present study, the femoral attachment of the ALL was independent from the anterolateral capsule but, after passing through the joint line, the ALL blended with the capsule. Therefore, when we harvested the ALLs to test the mechanical properties, the tibial attachment was included in some of the capsule structures. The ultimate load of the ALL in this study was $146.6 \mathrm{~N}$, which was smaller than the result of Rahnemai-Azar et al., who used the anterolateral knee capsule. The results of the ultimate load in other previous studies also involved smaller values than those obtained using the anterolateral knee capsule, but these results were varied, ranging from 49.9 to $204.8 \mathrm{~N}$ (Table 6). Among these, the results of not only the ultimate load but also the stiffness and elastic modulus in the study by Zens et al. showed significant disparity with those findings of both this study and other previous ones [20]. Meanwhile, the ultimate load in the study by Wytrykowski et al. was similar to that in this study [23], while the results of Kennedy at al. and Helito et al. were greater than found in this study [21,22]. The stiffness reported by Helito et al. was also similar to in this study, but the results of Kennedy et al. and Wytrykowski et al. were just $50 \%$ of the values recorded in this study. In this study, the most common failure site was the mid-substance (14/21) and there was no instance of failure reported at the femoral attachment. Most failures in the research by Wytrykowski et al. and Helito et al. similarly involved the mid-substance (15/15 and 10/14, respectively). 
Table 6. Comparisons of the mechanical properties and failure sites of the ALL across the literature.

\begin{tabular}{|c|c|c|c|c|c|c|c|c|c|}
\hline \multirow{2}{*}{ Author (Year) } & \multirow{2}{*}{$\mathbf{N}$} & \multirow{2}{*}{ Mean Age } & \multirow{2}{*}{ Ultimate Load (N) } & \multirow{2}{*}{ Stiffness (N/mm) } & \multirow{2}{*}{$\begin{array}{l}\text { Elastic Modulus } \\
\text { (MPa) }\end{array}$} & \multicolumn{4}{|c|}{ Failure Site } \\
\hline & & & & & & Femoral Attachment & Mid-Substance & Tibial Attachment & Bony Avulsion \\
\hline $\begin{array}{l}\text { This study } \\
\text { (2020) }\end{array}$ & 21 & 77.1 & $146.6 \pm 53.6$ & $42.6 \pm 21.3$ & $345.3 \pm 293.0$ & 0 & 14 & 7 & \\
\hline $\begin{array}{l}\text { Zens et al. } \\
\text { (2015) }\end{array}$ & 4 & 86.5 & $49.9 \pm 14.6$ & $2.6 \pm 0.9$ & $1.2 \pm 0.4$ & 4 & 0 & 0 & 0 \\
\hline $\begin{array}{l}\text { Kennedy et al. } \\
\text { (2015) }\end{array}$ & 15 & 58.2 & 175.0 & 20.0 & - & 4 & 4 & 1 & 6 \\
\hline $\begin{array}{c}\text { Wytrykowski et al. } \\
\text { (2016) }\end{array}$ & 15 & 54 & $141.0 \pm 40.6$ & $21.0 \pm 8.2$ & - & 0 & 15 & 0 & 0 \\
\hline $\begin{array}{l}\text { Helito et al. } \\
\text { (2016) }\end{array}$ & 14 & 62.6 & $204.8 \pm 114.9$ & $41.9 \pm 25.7$ & - & 2 & 10 & 1 & 1 \\
\hline
\end{tabular}


The results of the LCL and MCL properties of this study were compared with those of previous studies. Only previous investigations of the MCL that did not divide the MCL into superficial and deep layers were selected for consideration (Table 7). The ultimate load of the LCL of this study was smaller than that of other studies $(263.2 \mathrm{~N})$ and there was a great difference noted between the result of this study and the largest value in the literature, which was reported by Ciccone et al. $(460.0 \mathrm{~N})$. Whereas, the stiffness of this study $(69.7 \mathrm{~N})$ was the second-largest result after that reported by Ciccone et al. $(82.0 \mathrm{~N})$. In the case of the MCL, the ultimate load in this study $(498.6 \mathrm{~N})$ was similar to that of Marinozzi et al. (465.0 N); however, there was great disparity when matched with the result of Wilson et al. $(799.0 \mathrm{~N})$. Meanwhile, the stiffness values of this study were greater than those in other studies.

Table 7. Comparisons of the mechanical properties of the LCL and MCL.

\begin{tabular}{|c|c|c|c|c|c|c|}
\hline Ligament & Author (Year) & $\mathbf{N}$ & Mean Age & Ultimate Load (N) & $\begin{array}{l}\text { Stiffness } \\
(\mathrm{N} / \mathrm{mm})\end{array}$ & $\begin{array}{c}\text { Elastic } \\
\text { Modulus (MPa) }\end{array}$ \\
\hline \multirow{5}{*}{ LCL } & $\begin{array}{c}\text { This study } \\
(2020)\end{array}$ & 21 & 77.1 & $263.2 \pm 93.1$ & $69.7 \pm 22.9$ & $493.9 \pm 99.0$ \\
\hline & $\begin{array}{l}\text { Sugita et al. } \\
\text { (2001) }\end{array}$ & 10 & About 70 & $309.0 \pm 91.0$ & $58.1 \pm 22.8$ & - \\
\hline & $\begin{array}{l}\text { LaPrade et al. } \\
\text { (2005) }\end{array}$ & 8 & 57.5 & $295.0 \pm 96.0$ & $33.5 \pm 13.4$ & $183.5 \pm 110.7$ \\
\hline & $\begin{array}{l}\text { Ciccone et al. } \\
\text { (2006) }\end{array}$ & 13 & 70 & $460.0 \pm 163.0$ & $82.0 \pm 25.0$ & - \\
\hline & $\begin{array}{l}\text { Wilson et al. } \\
\text { (2012) }\end{array}$ & 9 & 81 & $392.0 \pm 104.0$ & $59.0 \pm 12.0$ & - \\
\hline \multirow{3}{*}{ MCL } & $\begin{array}{l}\text { This study } \\
\text { (2020) }\end{array}$ & 21 & 77.1 & $498.6 \pm 119.6$ & $72.0 \pm 23.5$ & $326.8 \pm 225.2$ \\
\hline & $\begin{array}{c}\text { Marinozzi et al. } \\
\text { (1983) }\end{array}$ & 5 & $55-90$ & $465.0 \pm 190.0$ & $60.0 \pm 22.0$ & - \\
\hline & $\begin{array}{l}\text { Wilson et al. } \\
\text { (2012) }\end{array}$ & 9 & 81 & $799.0 \pm 209.0$ & $63.0 \pm 14.0$ & - \\
\hline
\end{tabular}

Consequently, among all ligaments in this study, the biggest ultimate load was found on the MCL. The stiffness of the MCL was also similar to that of the LCL but that of the ALL was smaller than those of other ligaments. The elastic modulus of the MCL was similar to that of the ALL, while that of the LCL was larger; however, there was no significant difference between the three ligaments. There was no difference between the right and left sides among the different properties, but the properties of male cadavers were greater than those of female cadavers. Each ligament displayed a similar stiffness regardless of its size. However, when the stiffness is converted to the elastic modulus, which considers the cross-sectional area, it was harder to assess an average value because there was great deviation apparent due to the size of each ligament. Therefore, the stiffness should be preferentially considered when performing biomechanical simulations using these ligaments. There were some limitations in this study. Due to the ligaments that were harvested from the cadavers, their condition could differ from living human tissue, and the age of all the cadavers was old. Furthermore, in spite of the fact that the cross-sectional area of each ligament was not constant, the cross-sectional area was measured at the joint line as a rectangular shape for the ALL and MCL, and as an oval shape for the LCL. Finally, we performed the quasi-static test, and did not apply the various strain rates for the material test. Our strain rate was $10 \mathrm{~mm} / \mathrm{min}$. However, most of the comparable studies used different strain rates. Thus, it was difficult to completely compare our results with previous studies.

Author Contributions: Conceptualization, H.-J.C. and D.-S.K.; methodology, D.-S.K.; validation, H.-J.C.; formal analysis, H.-J.C.; investigation, D.-S.K.; writing-original draft preparation, H.-J.C. and D.-S.K.; writing-review and editing, D.-S.K. All authors have read and agreed to the published version of the manuscript.

Funding: This work was supported by the National Research Foundation of Korea (NRF) grant funded by the Korea government (MSIT) (NRF-2016R1D1A1B03931207). 
Conflicts of Interest: The authors declare no conflict of interest.

Ethics Statement: This research did not contain human and human-related material. Only donated cadavers (The Catholic University of Korea) were used, and all methods were carried out in accordance with relevant guidelines and regulations from the Catholic Institute for Applied Anatomy (Project identification number: R16-A014).

\section{References}

1. Flandry, F.; Hommel, G. Normal anatomy and biomechanics of the knee. Sports Med. Arthrosc. Rev. 2011, 19, 82-92. [CrossRef] [PubMed]

2. LaPrade, R.F.; Engebretsen, A.H.; Ly, T.V.; Johansen, S.; Wentorf, F.A.; Engebretsen, L. The anatomy of the medial part of the knee. J. Bone Joint Surg. Am. 2007, 89, 2000-2010. [CrossRef] [PubMed]

3. Amis, A.A. Anterolateral knee biomechanics. Knee Surg. Sports Traumatol. Arthrosc. 2017, 25, $1015-1023$. [CrossRef] [PubMed]

4. Kraeutler, M.J.; Welton, K.L.; Chahla, J.; LaPrade, R.F.; McCarty, E.C. Current concepts of the anterolateral ligament of the knee: Anatomy, biomechanics, and reconstruction. Am. J. Sports Med. 2018, 46, 1235-1242. [CrossRef]

5. Becker, R.; Hirschmann, M.T.; Karlsson, J. The role of ligament tension and sensomotoric system in total knee arthroplasty. Knee Surg. Sports Traumatol. Arthrosc. 2017, 25, 1663-1665. [CrossRef]

6. Riviere, C.; Iranpour, F.; Auvinet, E.; Howell, S.; Vendittoli, P.-A.; Cobb, J.; Parratte, S. Alignment options for total knee arthroplasty: A systematic review. Orthop. Traumatol. Surg. Res. 2017, 103, 1047-1056. [CrossRef]

7. Vicenti, G.; Solarino, G.; Carrozzo, M.; De Giorgi, S.; Moretti, L.; De Crescenzo, A.; Moretti, B. Major concern in the multiligament-injured knee treatment: A systematic review. Injury 2019, 50 (Suppl. S2), S89-S94. [CrossRef]

8. Kennedy, J.C.; Hawkins, R.J.; Willis, R.B.; Danylchuck, K.D. Tension studies of human knee ligaments. Yield point, ultimate failure, and disruption of the cruciate and tibial collateral ligaments. J. Bone Joint Surg. Am. 1976, 58, 350-355. [CrossRef]

9. Woo, S.L.; Hollis, J.M.; Adams, D.J.; Lyon, R.M.; Takai, S. Tensile properties of the human femur-anterior cruciate ligament-tibia complex. The effects of specimen age and orientation. Am. J. Sports Med. 1991, 19, 217-225. [CrossRef]

10. Chandrashekar, N.; Mansouri, H.; Slauterbeck, J.; Hashemi, J. Sex-based differences in the tensile properties of the human anterior cruciate ligament. J. Biomech. 2006, 39, 2943-2950. [CrossRef]

11. Harner, C.D.; Xerogeanes, J.W.; Livesay, G.A.; Carlin, G.J.; Smith, B.A.; Kusayama, T.; Kashiwaguchi, S.; Woo, S.L. The human posterior cruciate ligament complex: An interdisciplinary study. Ligament morphology and biomechanical evaluation. Am. J. Sports Med. 1995, 23, 736-745. [CrossRef] [PubMed]

12. Race, A.; Amis, A.A. The mechanical properties of the two bundles of the human posterior cruciate ligament. J. Biomech. 1994, 27, 13-24. [CrossRef]

13. Trent, P.S.; Walker, P.S.; Wolf, B. Ligament length patterns, strength, and rotational axes of the knee joint. Clin. Orthop. Relat. Res. 1976, 117, 263-270. [CrossRef]

14. Butler, D.L.; Kay, M.D.; Stouffer, D.C. Comparison of material properties in fascicle-bone units from human patellar tendon and knee ligaments. J. Biomech. 1986, 19, 425-432. [CrossRef]

15. Robinson, J.R.; Bull, A.M.; Amis, A.A. Structural properties of the medial collateral ligament complex of the human knee. J. Biomech. 2005, 38, 1067-1074. [CrossRef]

16. Wilson, W.T.; Deakin, A.H.; Payne, A.P.; Picard, F.; Wearing, S.C. Comparative analysis of the structural properties of the collateral ligaments of the human knee. J. Orthop. Sports Phys. Ther. 2012, 42, 345-351. [CrossRef]

17. Vincent, J.P.; Magnussen, R.A.; Gezmez, F.; Uguen, A.; Jacobi, M.; Weppe, F.; Al-Saati, M.F.; Lustig, S.; Demey, G.; Servien, E.; et al. The anterolateral ligament of the human knee: An anatomic and histologic study. Knee Surg. Sports Traumatol. Arthrosc. 2012, 20, 147-152. [CrossRef]

18. Claes, S.; Vereecke, E.; Maes, M.; Victor, J.; Verdonk, P.; Bellemans, J. Anatomy of the anterolateral ligament of the knee. J. Anat. 2013, 223, 321-328. [CrossRef]

19. Cho, H.J.; Kwak, D.S. Anatomical consideration of the anterolateral ligament of the knee. Biomed. Res. Int. 2019, 2019, 5740473. [CrossRef] 
20. Zens, M.; Feucht, M.J.; Ruhhammer, J.; Bernstein, A.; Mayr, H.O.; Südkamp, N.P.; Woias, P.; Niemeyer, P. Mechanical tensile properties of the anterolateral ligament. J. Exp. Orthop. 2015, 2, 7. [CrossRef]

21. Kennedy, M.I.; Claes, S.; Freitas Fuso, F.A.; Williams, B.T.; Goldsmith, M.T.; Lee Turnbull, T.; Wijdicks, C.A.; LaPrade, R.F. The anterolateral ligament: An anatomic, radiographic, and biomechanical analysis. Am. J. Sports Med. 2015, 43, 1606-1615. [CrossRef] [PubMed]

22. Helito, C.P.; Bonadio, M.B.; Rozas, J.S.; Wey, J.M.P.; Pereira, C.A.M.; Cardoso, T.P.; Pécora, J.R.; Camanho, G.L.; Demange, M.K. Biomechanical study of strength and stiffness of the knee anterolateral ligament. BMC Musculoskelet. Disord. 2016, 17, 193. [CrossRef] [PubMed]

23. Wytrykowski, K.; Swider, P.; Reina, N.; Murgier, J.; Laffosse, J.M.; Chiron, P.; Cavaignac, E. Cadaveric study comparing the biomechanical properties of grafts used for knee anterolateral ligament reconstruction. Arthroscopy 2016, 32, 2288-2294. [CrossRef] [PubMed]

24. Chong, S.; Kwak, D.-S.; Balasubramanian, D.; Song, Y.D.; Na, Y.G.; Kim, T.K. A new femoral fixation device for anterior cruciate ligament reconstruction using the outside-in technique and hamstring tendon graft: A comparison between two devices in cadaveric human knee models. Knee 2017, 24, 925-932. [CrossRef]

25. Dodds, A.L.; Halewood, C.; Gupte, C.M.; Williams, A.; Amis, A.A. The anterolateral ligament: Anatomy, length changes and association with the Segond fracture. Bone Joint J. 2014, 96, 325-331. [CrossRef]

26. Hughston, J.C.; Andrews, J.R.; Cross, M.J.; Moschi, A. Classification of knee ligament instabilities. Part II. The lateral compartment. J. Bone Joint Surg. Am. 1976, 58, 173-179. [CrossRef]

27. Spencer, L.; Burkhart, T.A.; Tran, M.N.; Rezansoff, A.J.; Deo, S.; Caterine, S.; Getgood, A.M. Biomechanical analysis of simulated clinical testing and reconstruction of the anterolateral ligament of the knee. Am. J. Sports Med. 2015, 43, 2189-2197. [CrossRef]

28. Arnoux, P.-J.; Subit, D.; Masson, C.; Chabrand, P.; Brunet, C. Knee ligaments mechanics. Rev. Eur. Élém. Finis 2012, 14, 577-600. [CrossRef]

29. Kittl, C.; Inderhaug, E.; Williams, A.; Amis, A.A. Biomechanics of the anterolateral structures of the knee. Clin. Sports Med. 2018, 37, 21-31. [CrossRef]

30. Rahnemai-Azar, A.A.; Miller, R.M.; Guenther, D.; Fu, F.H.; Lesniak, B.P.; Musahl, V.; Debski, R.E. Structural properties of the anterolateral capsule and iliotibial band of the knee. Am. J. Sports Med. 2016, 44, 892-897. [CrossRef]

(C) 2020 by the authors. Licensee MDPI, Basel, Switzerland. This article is an open access article distributed under the terms and conditions of the Creative Commons Attribution (CC BY) license (http://creativecommons.org/licenses/by/4.0/). 